\title{
Iron oxide nanoparticles and magnetic field exposure promote functional recovery by attenuating free radical-induced damage in rats with spinal cord transection
}

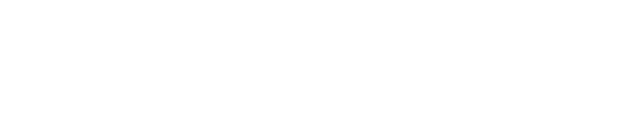

Ajay Pal'

Anand Singh ${ }^{2}$

Tapas C Nag

Parthaprasad

Chattopadhyay ${ }^{2}$

Rashmi Mathur'

Suman Jain'

'Department of Physiology,

${ }^{2}$ Department of Biochemistry,

${ }^{3}$ Department of Anatomy, All India

Institute of Medical Sciences,

New Delhi, India
Correspondence: Suman Jain

Department of Physiology,

All India Institute of Medical Sciences,

Ansari Nagar, New Delhi I I0029, India

Tel +9| | | 26593229

Fax +9| || 2658864 |

Email sumanjain 10@gmail.com
Background: Iron oxide nanoparticles (IONPs) can attenuate oxidative stress in a neutral $\mathrm{pH}$ environment in vitro. In combination with an external electromagnetic field, they can also facilitate axon regeneration. The present study demonstrates the in vivo potential of IONPs to recover functional deficits in rats with complete spinal cord injury.

Methods: The spinal cord was completely transected at the T11 vertebra in male albino Wistar rats. Iron oxide nanoparticle solution $(25 \mu \mathrm{g} / \mathrm{mL})$ embedded in $3 \%$ agarose gel was implanted at the site of transection, which was subsequently exposed to an electromagnetic field $(50 \mathrm{~Hz}$, $17.96 \mu \mathrm{T}$ for two hours daily for five weeks).

Results: Locomotor and sensorimotor assessment as well as histological analysis demonstrated significant functional recovery and a reduction in lesion volume in rats with IONP implantation and exposure to an electromagnetic field. No collagenous scar was observed and IONPs were localized intracellularly in the immediate vicinity of the lesion. Further, in vitro experiments to explore the cytotoxic effects of IONPs showed no effect on cell survival. However, a significant decrease in $\mathrm{H}_{2} \mathrm{O}_{2}$-mediated oxidative stress was evident in the medium containing IONPs, indicating their free radical scavenging properties.

Conclusion: These novel findings indicate a therapeutic role for IONPs in spinal cord injury and other neurodegenerative disorders mediated by reactive oxygen species.

Keywords: secondary damage, oxidative stress, electromagnetic field, cytotoxicity, neurodegeneration, pain

\section{Introduction}

The primary injury caused by a spinal cord lesion is generally followed by secondary damage that results in a number of morphological, physiological, and biochemical changes, including inflammation, excitotoxicity, cavitations, disruption of neurological pathways, demyelination, and cell death at the site of the lesion. ${ }^{1-12}$ Cyst formation and robust infiltration of fibroblasts result in formation of fibrous scar tissue that creates a physical barrier, ${ }^{13,14}$ preventing any severed axons or collateral branches of uninjured axons from growing past the area of the lesion. Therefore, reduction in the formation of fibrous scar tissue or secondary damage is positively correlated with functional recovery. ${ }^{15,16}$

Iron oxide nanoparticles (IONPs) have been widely used in medical diagnostics and therapeutics because of their unique size, magnetic properties, and ability to interact with a number of biomolecules. They play a vital role in vivo, especially as 
contrast agents in magnetic resonance and in targeted drug delivery. ${ }^{17,18}$ More recently, in vitro experiments have demonstrated their potential to promote regeneration and axon growth, thereby helping to bridge the gap at the injury site. ${ }^{19-21}$ For this process to occur in vivo, it is necessary for IONPs to be able to be loaded in neural cells and that they have negligible cytotoxicity. When internalized, they have been found to show concentration-dependent and time-dependent cytotoxicity. ${ }^{22}$ In cultured murine macrophage cells, IONP concentrations above $100 \mu \mathrm{g} / \mathrm{mL}$ for 3-6 hours generate reactive oxygen species leading to cell death. The cytotoxic effects of IONPs also vary with the $\mathrm{pH}$ of the medium. ${ }^{23}$ They can enhance $\mathrm{H}_{2} \mathrm{O}_{2}$-induced cell damage dramatically through their peroxidase-like activity in an acidic environment, and at neutral $\mathrm{pH}$, they catalyze the breakdown of $\mathrm{H}_{2} \mathrm{O}_{2}$ into $\mathrm{H}_{2} \mathrm{O}$ and $\mathrm{O}_{2}$, thereby reducing oxidative stress. ${ }^{24}$

Retention and accumulation of IONPs in cells can be enhanced by an external magnetic field (MF), providing mechanical tensile forces that may cause axonal sprouting. ${ }^{19,25}$ An MF can also magnetize nanoparticles such that their beneficial effects can be focused to the site of injury. An MF can noninvasively create electric fields in deep underlying structures, thereby modulating oxidative stress, apoptosis, release of neurotransmitters, secretion of neurotrophic factors, and axonal growth. ${ }^{26-31}$ In rat models of spinal cord injury (SCI), exposure to a low intensity MF results in significant improvement in locomotor, sensorimotor, and autonomic function. ${ }^{32-36}$ Stimulation of the motor cortex by repetitive transcranial magnetic stimulation is beneficial, especially in lower thoracic SCI lesions, because it activates the central pattern generator via descending serotonin pathways. ${ }^{28}$ In vitro, exposure to an MF increases the overall viability of mouse monoclonal hippocampal HT22 cells and has a neuroprotective effect against oxidative stressors. ${ }^{26}$

The present study was designed to explore the potential of IONPs in the functional recovery from SCI in an in vivo rat model. IONPs embedded in agarose gel were implanted in a complete SCI rat model at the site of injury and exposed to an MF for five weeks. Locomotor and sensorimotor behavioral tests were done weekly to monitor the temporal pattern of recovery, if any. Tissue and cellular localization of the IONPs was done by Prussian blue staining and transmission electron microscopy (TEM). The extent and morphology of the lesion was analyzed in cresyl violet-stained sections. In a separate in vitro study to elucidate the possible cytotoxic effects of IONPs, human glioblastoma multiforme (GBMU87) cells were incubated with varying concentrations of IONPs for different time periods. Finally, the effect of IONPs on viability of the cells following $\mathrm{H}_{2} \mathrm{O}_{2}$-induced oxidative stress was observed.

\section{Materials and methods TEM characterization of IONPs}

IONPs were sourced from Sigma-Aldrich (St Louis, MO, USA). The characteristics of the IONPs as reported by the manufacturer were iron (II, III) oxide nanoparticle $\left(\mathrm{Fe}_{3} \mathrm{O}_{4}\right)$ solution, with $2.5 \%-3.5 \%$ as solid material, concentration in water; diameter $10-50 \mathrm{~nm}$ (hydrodynamic diameter $\geq 1 \%$ mean volume); z-average about $30 \mathrm{~nm}$; and particle size $6.5 \pm 3.0 \mathrm{~nm}$ (including iron-oxide-nucleus). TEM was performed using a Morgagni 268D device (Fei Company, Amsterdam, The Netherlands). Next, a $10 \mu \mathrm{L}$ sample was placed on a carbon-coated copper grid and allowed to dry for 30 minutes, with the excess liquid being wicked away with filter paper. Grids were stored in a desiccator prior to microscopic observation. Likewise, agarose gel containing IONP solution was also placed on a carbon-coated grid and the size of the nanoparticles in the samples was determined using image processing software (Soft Imaging Systems GmbH, Münster, Germany).

\section{In vitro experiments}

\section{Cell lines and cultures}

A GBM-U87 cell line was obtained from the American Type Culture Collection (HTB-14, Manassas, VA, USA). This particular cell line was used for in vitro testing of the toxicity of the nanoparticles because it was of central nervous system origin, similar to spinal cord tissue. The cells were cultured in Dulbecco's Modified Eagle's Medium (Gibco ${ }^{\circledR}$, Life Technologies, Carlsbad, CA, USA) supplemented with $10 \%(\mathrm{v} / \mathrm{v})$ heat-inactivated fetal bovine serum, $100 \mathrm{U} / \mathrm{mL}$ penicillin, and $100 \mu \mathrm{g} / \mathrm{mL}$ streptomycin at $37^{\circ} \mathrm{C}$ in a humidified $5 \% \mathrm{CO}_{2}$ incubator (BOD Incubator, SANCO, Delhi, India), and passaged once every 2-3 days.

\section{Cell survival assay}

The in vitro cytotoxic effect of varying concentrations of IONPs was checked at different incubation times by cell proliferation assay using an XTT cell titer kit (Promega, Madison, WI, USA). First, 5000 cells were plated in each well of a 96-well culture plate. After 24 hours, IONPs were added to the cells at concentrations of 10, 25, 50 and $100 \mu \mathrm{g} / \mathrm{mL}$ in triplicate. The cells were incubated for 24 , or 48 , or 72 hours, after which an XTT \{2,3-bis (2-methoxy4-nitro-5-sulfophenyl)-5-[(phenylamino) carbonyl]-2Htetrazolium hydroxide assay was done at each time point 
to check for cell survival. The absorbance of the sample was measured at $490 \mathrm{~nm}$. In a separate experiment using the same conditions, a viable cell count was done using the trypan blue exclusion method to see whether absorbance of iron present in the cells can affect absorbance of formazan orange.

\section{Hydrogen peroxide-induced oxidative stress assay}

The autocatalytic and free radical scavenging properties of the IONPs were further demonstrated in an $\mathrm{H}_{2} \mathrm{O}_{2}$-induced oxidative injury model using a GBM-U87 cell line. A $10 \mathrm{mM} \mathrm{H}_{2} \mathrm{O}_{2}$ solution was added for one hour to both a control culture and a $25 \mu \mathrm{g} / \mathrm{mL}$ IONP-treated culture at 24, 48, and 72 hours. Cell viability was assayed after one hour of treatment with $\mathrm{H}_{2} \mathrm{O}_{2}$, and viable cells were counted using the trypan blue exclusion method.

\section{Viable cell counts}

To determine whether the presence of IONPs had an effect on cell survival, GBM-U87 cells were cultured in 96-well plates (Corning Incorporated Life Sciences, Tewksbury, MA, USA) at a seeding density of 5000 cells/well in $100 \mu \mathrm{L}$ culture medium and allowed to proliferate for 24 hours. After 24 hours, IONPs were added to the cells at a concentration of $10,25,50$, or $100 \mu \mathrm{g} / \mathrm{mL}$ in triplicate and incubated for 24,48 , or 72 hours. The cells were then trypsinized and collected. Counting was done using a Neubauer hemocytometer (Hausser Scientific Company, Horsham, PA, USA) and the trypan blue exclusion method to determine the number of viable cells per $\mathrm{mL}$ in each group. The effect of $\mathrm{H}_{2} \mathrm{O}_{2}$ on cell viability was also tested. After 24, 48, and 72 hours of treatment with $25 \mu \mathrm{g} / \mathrm{mL}$ IONPs, $10 \mathrm{mM} \mathrm{H}_{2} \mathrm{O}_{2}$ was added to the control and IONP-treated cultures. One hour later, viable cells were harvested and counted at each time point using the trypan blue exclusion method as described above.

\section{Animals}

Adult male Wistar rats ( $\mathrm{n}=66$, weighing 200-250 g) were obtained from the Central Animal Facility (All India Institute of Medical Sciences, New Delhi, India), and housed in a room with controlled temperature $\left(24^{\circ} \mathrm{C} \pm 2{ }^{\circ} \mathrm{C}\right)$, humidity $(60 \%-70 \%)$, and a light/dark cycle (14 hours light and 10 hours dark). Food and water were available ad libitum. The study was approved by the animal ethics committee at the All India Institute of Medical Sciences New Delhi, India. The rats were divided into four groups, ie, SCI only (SCI, $n=18)$, SCI with IONP implantation (NP, $n=15)$, SCI with
MF exposure $(M F, n=15)$, and SCI with both IONP implantation and $\mathrm{MF}$ exposure $(\mathrm{NP}+\mathrm{MF}, \mathrm{n}=18)$.

\section{Surgery}

The rats were anesthetized using an intraperitoneally administered mixture of ketamine $60 \mathrm{mg} / \mathrm{kg}$ and xylazine $10 \mathrm{mg}$ / $\mathrm{kg}$. The thoracic area was shaved and cleaned with povidoneiodine solution and 70\% alcohol. An incision extending from the upper thoracic region to the upper lumbar region was made, and the spinal cord was transected at the T11 vertebra with the help of microscissors. After transection, the cavity was explored with a glass seeker to ensure that no connection existed between the ends of the transected cord. The skin and underlying tissue was closed in layers with 1-0 silk sutures (Ethicon, non absorbable surgical suture, Johnson \& Johnson Ltd, Mumbai, India), and antibiotic powder (neosporin antibiotic powder, GlaxoSmithKline Pharmaceuticals Ltd., Bangalore, India) was applied locally. During surgery, the body temperature was maintained using controlled-heating pads (CMA-150, CMA Microdialysis, North Chelmsford, MA, USA). In the NP and NP + MF groups, a $2 \mathrm{~mm}$ sample of $25 \mu \mathrm{g} / \mathrm{mL}$ IONPs embedded in $3 \%$ agarose hydrogel was implanted at the site of injury during surgery, whereas only gel was implanted in the SCI and MF groups. ${ }^{37,38}$

The rats were injected subcutaneously with $5 \mathrm{~mL}$ of saline to prevent dehydration and injected intramuscularly with gentamicin-cefazolin $20 \mathrm{mg} / \mathrm{kg}$ for five days following surgery. ${ }^{39}$ The urinary bladder was manually evacuated thrice daily until spontaneous voiding was achieved. General body condition, ie, food intake, water intake, and body weight, were recorded daily.

Twenty-four hours following injury, rats in the MF and $\mathrm{NP}+\mathrm{MF}$ groups were exposed to an MF $(17.96 \mu \mathrm{T}, 50 \mathrm{~Hz}$, two hours daily) in a specifically designed chamber (All India Institute of Medical Sciences) for five weeks. Briefly, the chamber had two pairs of circular coils of equal diameter $(1.0 \mathrm{~m})$ wound on the same cylindrical surface. The current ratio between the outer and inner pairs of coils was 2.2604 and a simple turn ratio of 9/4/4/9 yielded a uniform $\mathrm{MF}$ of $17.96 \mu \mathrm{T}$ in the center of the chamber. ${ }^{40}$ The rats were kept in a Plexiglas enclosure (All India Institute of Medical Sciences) and placed on the wooden platform in the middle of the MF chamber.

\section{Assessment of locomotor function}

Spontaneous hind limb function was assessed every week and scored by two observers blinded to treatment group 
using the Basso, Beattie, and Bresnahan locomotor rating scale. ${ }^{41}$ The rats were placed in the center of an open field and their movement was recorded in the camera for four minutes. The data were scored and analyzed off line as per the scoring method.

To assess their ability to balance and coordinate stepping, the rats were placed on a single moving wheel for three trials per session on three days per week. The wheel was set at a constant speed of $4 \mathrm{rpm}$ for 300 seconds and the time of fall was recorded in seconds. Each trial was scored individually and averaged for a final score per session. ${ }^{42}$ An intertrial interval of 300 seconds was set.

\section{Assessment of sensorimotor function}

Sensitivity to noxious thermal stimuli was assessed on alternate weeks using the hot plate test. A hot plate analgesia monitor (Omnitech, Charlotte, NC, USA) surrounded by a Plexiglas cage was maintained at $52^{\circ} \mathrm{C} \pm 1{ }^{\circ} \mathrm{C}$ using a thermostat. The latency of hind paw withdrawal was recorded by a timer. The cutoff time was set at 30 seconds to avoid damage to tissue in the plantar region. ${ }^{43}$

\section{Assessment of autonomic function}

Urinary bladder function was assessed daily according to the method described by Liebscher, with modifications. ${ }^{44}$ The four categories used to score urinary bladder function were as follows: spontaneous evacuation, partial assistance for evacuation, total assistance for evacuation, and bursting of the bladder. If a rat was unable to evacuate, manual evacuation was performed three times a day until evacuation started spontaneously.

\section{Histology}

After five weeks, the rats were deeply anesthetized by intraperitoneal administration of ketamine $70 \mathrm{mg} / \mathrm{kg}$ and transcardially perfused with cold saline $\left(4^{\circ} \mathrm{C}\right)$ followed by $4 \%$ paraformaldehyde in phosphate-buffered saline $0.1 \mathrm{M}$ ( $\mathrm{pH}$ 7.4). The vertebral column with the spinal cord was isolated from T5 to L5 and post-fixed in the same fixative for 24 hours at $4^{\circ} \mathrm{C}$. A $10 \mathrm{~mm}$ long spinal cord tissue block containing the lesion epicenter was taken and processed for cryosectioning. Sagittal sections $(16 \mu \mathrm{m})$ were obtained and mounted on poly-L-lysine-coated slides.

Alternate sections from the spinal cord tissue of each rat were stained with cresyl violet using a standard protocol to assess the extent of the lesion. The total area of lesional damage in these sections was traced using a microscope (Eclipse 80i, Nikon, Tokyo, Japan) and measured using NIS Element software (Nikon). The area marked by dense gliosis, cysts, or blank (other than where the agarose gel was introduced) was considered for calculation of the total area damaged. ${ }^{41}$ To calculate the total volume of damaged tissue, the total area of the single section was multiplied with the number of sections per spinal cord and the thickness of the single section. Assessments were made by an investigator unaware of treatment allocation.

\section{Prussian blue iron staining}

Tissue sections were stained for iron using Prussian blue staining to localize the site of the IONPs. Briefly, the frozen tissue sections were warmed to room temperature and dipped in distilled water for 10 minutes for rehydration. Hydrated tissue sections were then dipped in a $1: 1$ solution of $10 \%$ potassium ferrocyanide (Merck Millipore, Billerica, MA, USA) and 20\% $\mathrm{HCl}$ (Merck Millipore) for 15 minutes. The slides were rinsed for five minutes in distilled water and counterstained with nuclear fast red. The sections were then dehydrated in 95\% ethanol, 100\% ethanol, and xylene (with two changes each for five minutes), then mounted with DPX (di-n-butyl phthalate in xylene) medium (Sigma-Aldrich) and coverslipped.

\section{Masson's trichrome staining}

Masson's trichrome staining was done to identify the presence of collagenous connective tissue at the injury site using an Accustain trichrome stain (Masson's kit, Catalog number HT15, Sigma-Aldrich) following the standard procedure recommended by the manufacturer.

\section{TEM of spinal cord tissue}

TEM was done to observe the localization of IONPs in spinal cord tissue cells in the NP + MF group. TEM specimens were prepared after sacrificing the rats, with transcardial perfusion, first with cold saline, then with $4 \%$ paraformaldehyde in phosphate-buffered saline $0.1 \mathrm{M}$ ( $\mathrm{pH} 7.4)$. The spinal cord tissue containing the lesion epicenter was then fixed in Karnovsky's fixative (TAAB Laboratories Equipment Ltd, Aldermaston, England) and processed using the standard protocol for TEM. The sections were stained with $2 \%$ uranyl acetate and lead citrate (TAAB Laboratories Equipment Ltd), and examined by TEM.

\section{Statistical analysis}

Statistical analysis was performed using Statistical Package for Social Sciences version 15 software (SPSS Inc, Chicago, IL, USA). The data are presented as the mean \pm standard 
deviation. The data were compared between the groups every week using one-way analysis of variance or the KruskalWallis test, with post hoc analysis using the Bonferroni test or Mann-Whitney $U$ test. Within-group data were assessed using repeated-measures analysis of variance, and the Kruskal-Wallis test was used for analysis of the Basso, Beattie, and Bresnahan scores and Rotarod results. The overall difference between the groups was analyzed using the generalized estimating equation. The Student's $t$-test was used to compare the data for cell viability and cell counting amongst the groups. A $P$ value less than 0.05 was considered to be statistically significant.

\section{Results}

The 66 rats used in this study were allocated to SCI and $\mathrm{NP}+\mathrm{MF}$ groups $(\mathrm{n}=18$ each) or to MF and NP groups ( $n=15$ each). Eight rats each from the SCI and NP groups, seven from the MF group, and four from the NP + MF group were euthanized because of self-biting/mutilation or urinary tract infection and/or blockage. No significant difference in preinjury baseline data was observed between the four treatment groups.

\section{Characterization of IONPs}

A TEM micrograph of IONPs is shown in Figure 1A. The size distribution was determined by measuring the diameters of IONPs randomly selected from the TEM micrographs. Although the IONPs became dispersed and aggregated after embedding in gel, the particle size was almost uniform,
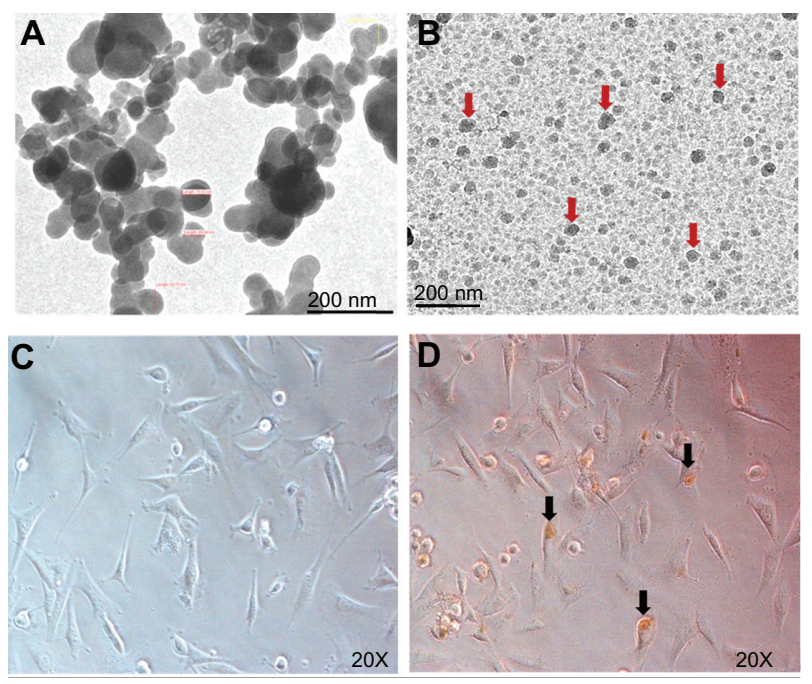

Figure I Transmission electron micrographs of naked IONPs (A) and IONPs (arrows) in gel (B). Images of GBM-U87 cells in an untreated culture (C) and after 24 hours of incubation with IONPs $25 \mu \mathrm{g} / \mathrm{mL}$ (D).

Note: Arrowhead indicates intracellular localization of IONPs.

Abbreviation: IONPs, iron oxide nanoparticles. with a spherical shape and an average diameter of $50 \mathrm{~nm}$ (Figure 1B). Photomicrographs of GBM-U87 cells after 24 hours of incubation with IONPs $(25 \mu \mathrm{g} / \mathrm{mL})$ showed intracellular localization (Figure 1C and D).

\section{In vitro experiments \\ Cytotoxicity assay}

GBM-U87 cells were treated with different concentrations of IONPs $(10,25,50$, and $100 \mu \mathrm{g} / \mathrm{mL})$. In comparison with the controls, treated cells did not show any significant difference in survival (Figure 2A) at different time intervals (24 hours $[P=0.989], 48$ hours $[P=0.739]$, and 72 hours $[P=0.359])$ at any of the concentrations used. Similar results were obtained by cell counting using the trypan blue exclusion method (Figure 2C). These results suggest that IONPs do not cause significant cell death even at concentrations as high as $100 \mu \mathrm{g} / \mathrm{mL}$.

\section{$\mathrm{H}_{2} \mathrm{O}_{2}$-induced oxidative stress assay}

The free radical scavenging properties of IONPs were assessed in vitro using the same cell line as that used to assess cell viability (ie, GBM-U87). We added $10 \mathrm{mM}$ $\mathrm{H}_{2} \mathrm{O}_{2}$ to the control and $25 \mu \mathrm{g} / \mathrm{mL}$ IONP-treated cultures for one hour and then determined cell viability. A significant reduction in cell viability was observed after addition of $\mathrm{H}_{2} \mathrm{O}_{2}(P=0.001$ at 24 hours and 48 hours and $P=0.0001$ at 72 hours, Figure 2B). However, treatment with IONPs significantly enhanced cell survival in comparison with $\mathrm{H}_{2} \mathrm{O}_{2}$ alone ( $P=0.002$ at 24 hours, $P=0.004$ at 48 hours, and $P=0.003$ at 72 hours, Figure $2 B$ ). Similar results were found for cell counting (Figure 2D). These findings demonstrate the free radical scavenging properties of the IONPs.

\section{General body condition}

Post-injury food and water intake decreased in all groups in comparison with baseline and remained at a lower level during the five-week observation period. Within-group analysis demonstrated a significant increase in food intake (SCI, $\mathrm{F}[4,36]=126.330, P=0.0001 ; \mathrm{MF}, \mathrm{F}[4,28]=37.967$, $P=0.0001 ; \mathrm{NP}, \mathrm{F}[4,24]=91.151, P=0.0001 ; \mathrm{NP}+$ $\mathrm{MF}, \mathrm{F}[4,52]=132.399, P=0.0001)$ and water intake (SCI, $\mathrm{F}[4,36]=169.893, P=0.0001 ; \mathrm{MF}, \mathrm{F}[4,28]=45.284$, $P=0.0001 ; \mathrm{NP}, \mathrm{F}[4,24]=289.619, P=0.0001 ; \mathrm{NP}+$ $\mathrm{MF}, \mathrm{F}[4,52]=143.492, P=0.0001)$ during the post-injury days in all groups, suggesting gradual spontaneous recovery (Table 1).

Analysis of variance showed a significant effect of MF exposure and IONP implantation on post-injury food and water intake 
A

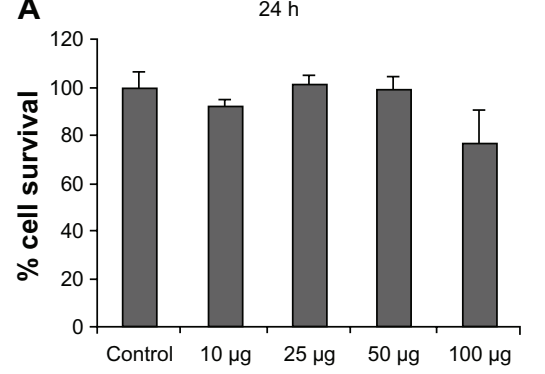

B

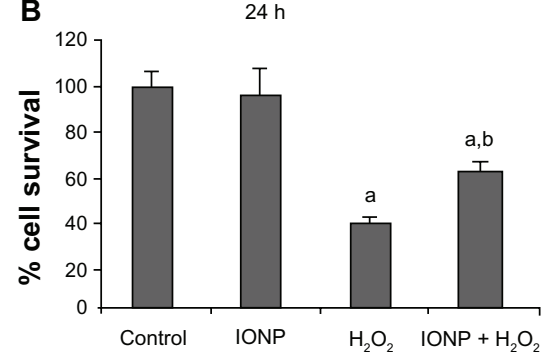

C

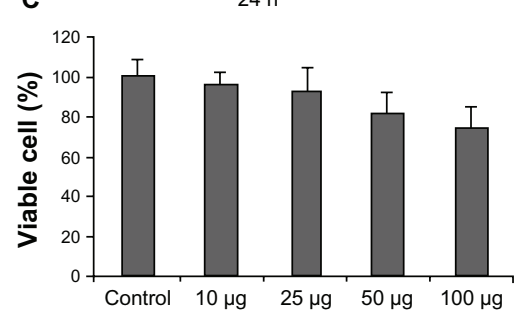

D

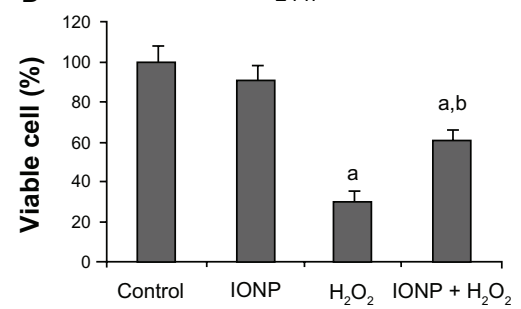

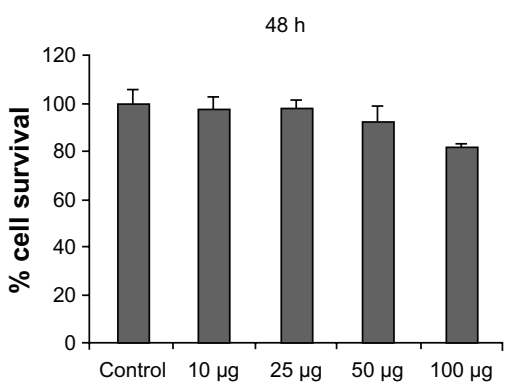
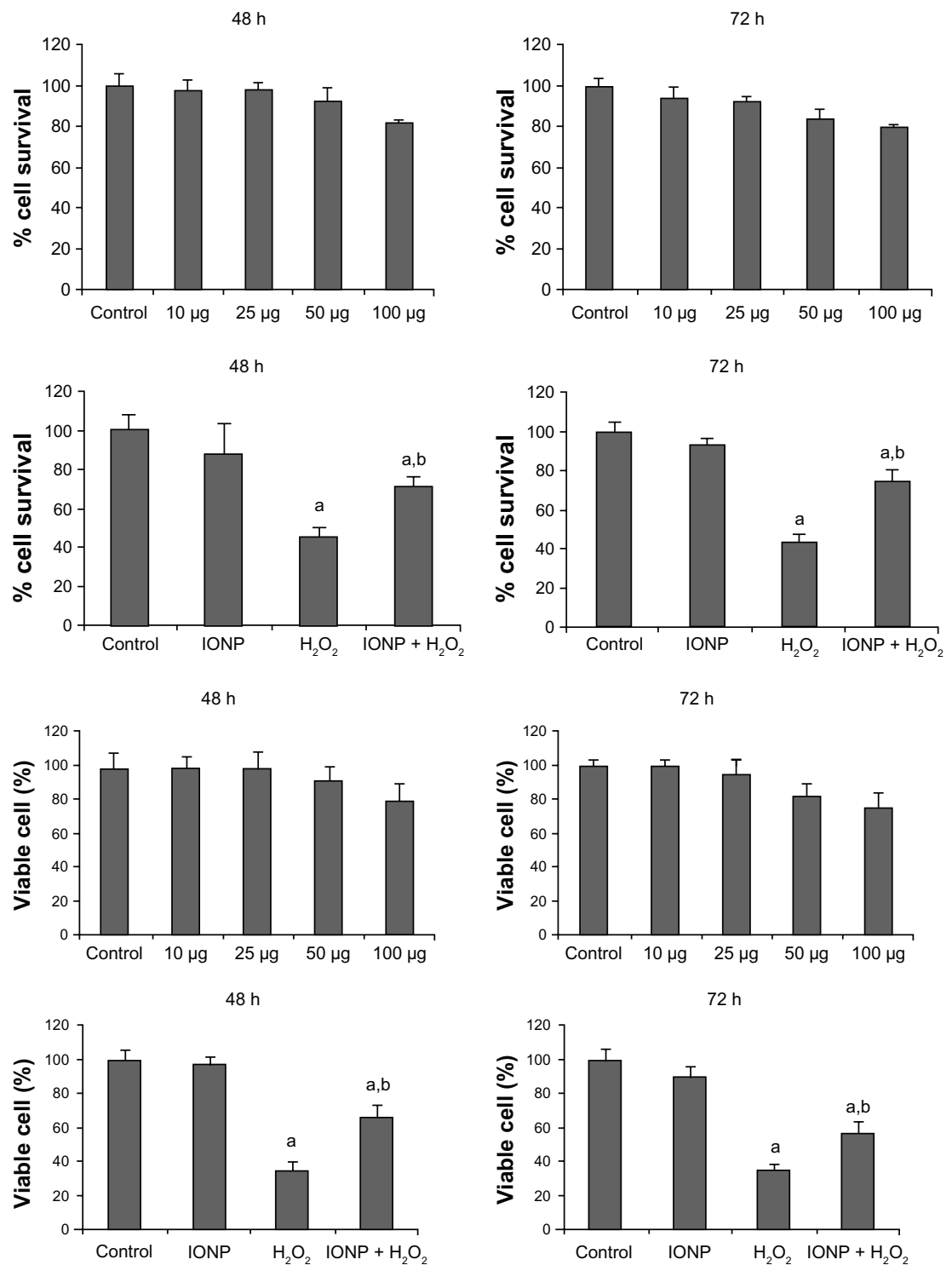

Figure 2 In vitro cell viability assay and cell counting with varying concentrations of IONPs (I0,25, 50, and I00 $\mu g / \mathrm{mL})$ and incubation for 24,48 , and 72 hours (A). There was no significant difference in percent viability at any of the time points or concentrations in comparison with controls. The cytotoxicity induced by $\mathrm{H}_{2} \mathrm{O}_{2} 10 \mathrm{mM}$ was attenuated by $25 \mu \mathrm{g} / \mathrm{mL}$ IONPs (B). Live cell counting with the trypan blue exclusion method using different concentrations of IONPs (C), showing no significant difference in percentage of viable cells observed at any of the time points or concentrations in comparison with the control. Cytotoxicity induced by $\mathrm{H}_{2} \mathrm{O}_{2} 10 \mathrm{mM}$ was attenuated by $25 \mu \mathrm{g} / \mathrm{mL}$ IONPs (D).

Notes: Statistical significance $(P<0.05)$ is shown by ${ }^{a}$ Control versus IONP, $\mathrm{H}_{2} \mathrm{O}_{2}$, IONP $+\mathrm{H}_{2} \mathrm{O}_{2}$; ${ }^{\text {b }} \mathrm{H}_{2} \mathrm{O}_{2}$ versus $\mathrm{NP}+\mathrm{H}_{2} \mathrm{O}_{2}$.

Abbreviations: IONPs, iron oxide nanoparticles; $\mathrm{H}_{2} \mathrm{O}_{2}$, hydrogen peroxide.

(food, F $[2,19]=6.093, P=0.009$; water, $\mathrm{F}[2,19]=6.923$, $P=0.006)$. Post hoc analysis demonstrated a significantly increased food intake in the NP + MF group from the first week onwards when compared with the SCI $(P=0.0001)$, NP ( $P=0.0001)$, and $\mathrm{MF}(P=0.0003)$ groups, with the MF group being significantly different from the SCI $(P=0.019)$ group only. Recovery of normal water intake was only observed in the $\mathrm{NP}+\mathrm{MF}$ group when compared with the SCI $(P=0.0001), \mathrm{NP}$ ( $P=0.0001)$, and MF $(P=0.004)$ groups.

Because post-injury rat body weight varied widely within each group, the change in body weight from baseline was calculated for each rat and subjected to statistical analysis. Following injury until the observation period of five weeks, a significant decrease $(P<0.001)$ in body weight was observed in all the groups in comparison with baseline. Within each group, body weight started increasing gradually from post-injury week 4 (SCI, F $[4,36]=7.265, P=0.0001$; MF, F $[4,28]=4.441, P=0.007$; NP, F $[4,24]=29.989$, $P=0.0001) ; \mathrm{NP}+\mathrm{MF},(\mathrm{F}[4,52]=30.811, P=0.0001)$, suggesting spontaneous recovery. However, treatment had a significant effect on body weight (F $[2,19]=7.026, P=0.005)$. On post hoc analysis, the decrease in body weight following 


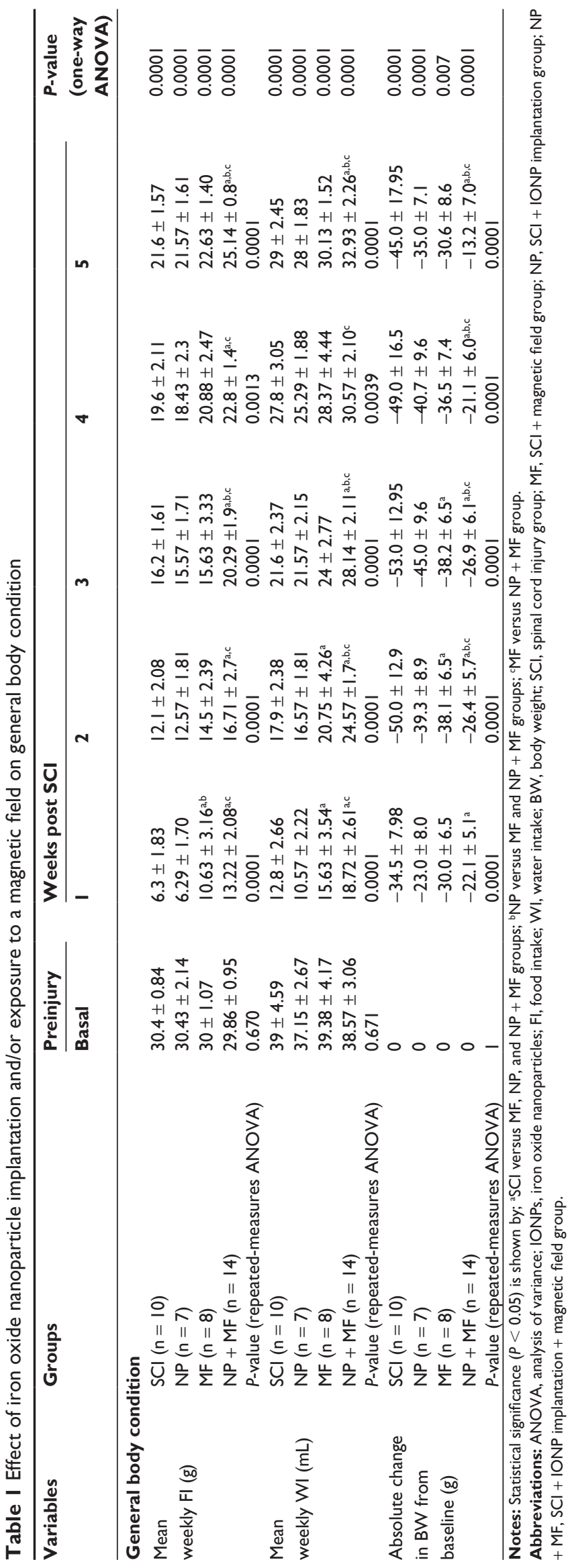

injury and recovery thereafter was significant in both the MF and NP + MF groups as compared with the SCI group $(P<0.001)$.

\section{Locomotor function}

The Basso, Beattie, and Bresnahan locomotor rating score decreased significantly $(P<0.0001)$ from a preinjury baseline of 21 in all the groups to 0-2 post-injury week 1, although a gradual but significant improvement in scores was observed during the post-injury weeks in all the groups (SCI, $\chi^{2}=37.87, P=0.0001 ; \mathrm{MF}, \chi^{2}=31.82, P=0.0001$; NP, $\left.\chi^{2}=27.23, P=0.0001 ; \mathrm{NP}+\mathrm{MF}, \chi^{2}=56.00, P=0.0001\right)$. A statistically significant effect of IONP implantation combined with MF exposure was observed $\left(\chi^{2}=224.89\right.$, $P=0.0001)$. In the NP + MF group, there was a significant $(P=0.0001)$ increase in the scores, in comparison with the other groups, from post-injury week 1 , which was maintained throughout the observation period. Basso, Beattie, and Bresnahan scores were also significantly $(P=0.001)$ higher in the MF group in comparison with the SCI and NP groups, suggesting an improvement in locomotor behavior. No significant difference was observed between the SCI and NP groups ( $P=0.079$, Figure 3A).

Although a gradual improvement in stay time using the Rotarod test was observed in all the groups over the observation period of five post-injury weeks (SCI, $\chi^{2}=13.30$, $P=0.0001$; NP, $\chi^{2}=13.26, P=0.010 ;$ MF, $\chi^{2}=11.30$, $\left.P=0.023 ; \mathrm{NP}+\mathrm{MF}, \chi^{2}=50.11, P=0.0001\right)$, there was a significant decrease in the stay time post-injury as compared with baseline values before injury $(P=0.0001)$. A significant effect of IONP implantation combined with MF exposure was observed even at post-injury week 1 in comparison with the SCI, NP, and MF groups $(P=0.0001)$. This increase in stay time was maintained until five weeks, indicating a beneficial effect of IONP implantation. No significant difference in stay time was observed between the SCI and NP or MF groups $(P=0.520$, Figure $3 \mathrm{~B})$.

\section{Sensorimotor function}

In comparison with baseline values, hind paw withdrawal latency in response to thermal stimulation decreased significantly $(P<0.001)$ in all groups post- injury. Although a gradual increase was observed in all groups over the post-injury weeks $(\mathrm{SCI}, \mathrm{F}[2,18]=26.711, P=0.0001$; $\mathrm{NP}, \mathrm{F}[2,12]=25.002, P=0.0001 ; \mathrm{MF}, \mathrm{F}[2,14]=33.328$, $P=0.0001 ; \mathrm{NP}+\mathrm{MF}, \mathrm{F}[2,26]=91.769, P=0.0001)$, hind paw withdrawal latency was significantly higher in the NP + MF group than in the other three groups 
A

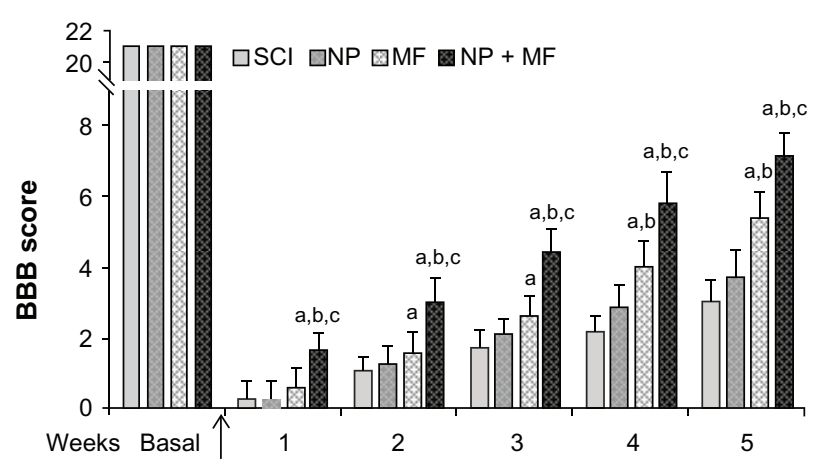

C

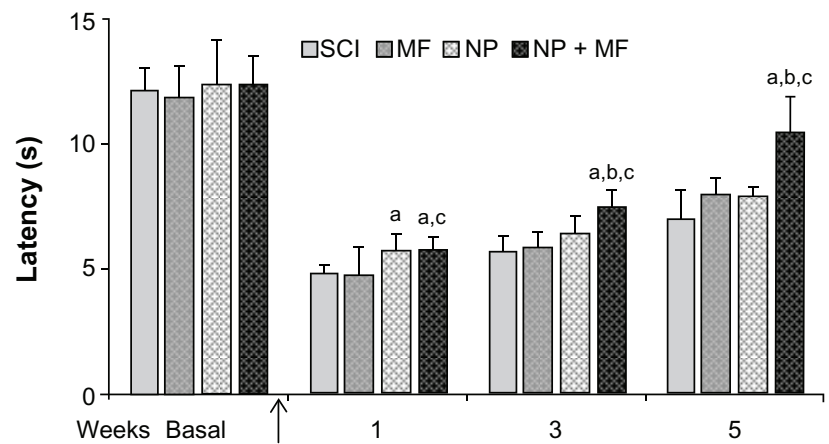

B

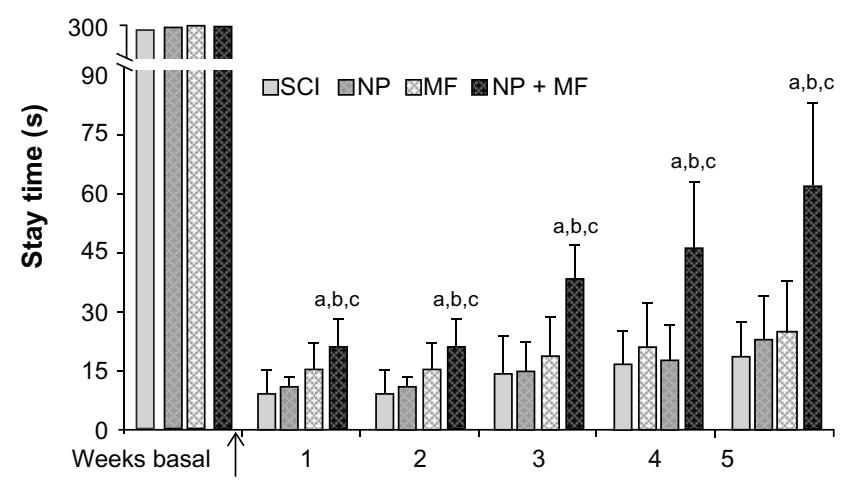

D

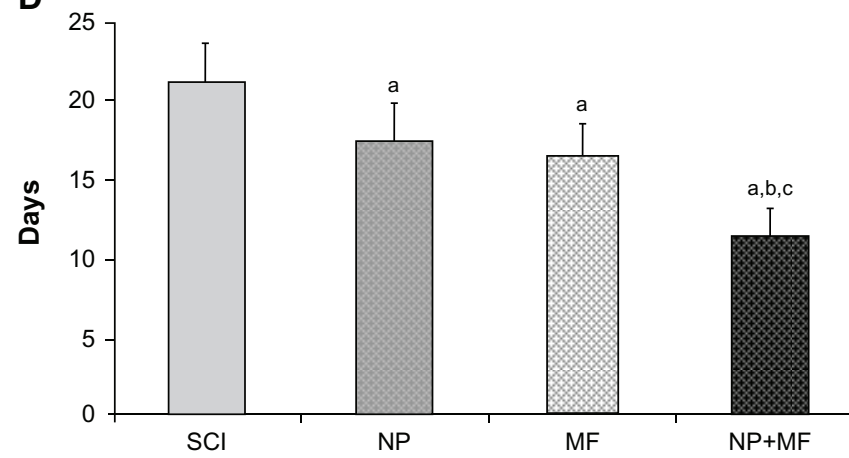

Figure 3 Effect of IONP implantation and MF exposure on mean ( \pm SD) BBB score $(\mathbf{A})$ and mean $( \pm$ SD) time of stay on the moving Rotarod (B). Significant recovery was observed in both these tests after IONP implantation and MF exposure starting from week I which continued throughout the observation period. Mean ( \pm SD) hind paw withdrawal latency $(\mathbf{C})$ and urinary bladder function $(\mathbf{D})$ were also significantly better in the NP + MF group.

Notes: Statistical significance $(P<0.05)$ is shown by ${ }^{a} \mathrm{SCl}$ versus MF, NP, NP + MF groups; ${ }^{b} \mathrm{NP}$ versus MF/NP + MF groups; ${ }^{\mathrm{C}} \mathrm{MF}$ versus NP + MF group.

Abbreviations: BBB, Basso, Beattie, and Bresnahan locomotor rating; IONPs, iron oxide nanoparticles; SD, standard deviation; SCl, spinal cord injury group; MF, SCI + magnetic field group; NP, SCl + IONP implantation group; NP + MF, SCI + IONP implantation + magnetic field group.

$(\mathrm{F}[3,35]=18.57, P=0.0001)$. No significant difference was observed in hind paw withdrawal latency between the SCI and MF groups $(P=0.374$, Figure 3C).

\section{Autonomic function}

Achievement of complete spontaneous voiding of the bladder also improved on treatment $(\mathrm{F}[3,35]=44.38, P=0.0001)$. Post hoc analysis revealed that the most rapid recovery occurred in the NP + MF group $(P<0.001)$, although the MF and NP groups also recovered earlier than the SCI group $(P<0.001$, Figure 3D).

\section{Histology}

The injury profiles (the degree of rostral and caudal tissue loss in relation to the epicenter) were largely symmetrical and consistent within each group (Figure 4A). The overall shape of the injuries was ovoid, showing very little/no sparing of tissue near the injury epicenter. However, the total volume of the lesion differed significantly $(F=129.12$, $P=0.0001$ ) between the groups, being least in the NP $+\mathrm{MF}$ group (Figure 5). Few viable motor neurons were evident in this group at a distance of $1 \mathrm{~mm}$ from the epicenter (Figure 4B).

Further, in the SCI and NP groups, either dense collagenous connective tissue with a sieve-like structure or a single cystic cavity surrounded by a thick layer of collagen was observed in trichrome-stained sections from the epicenter of the lesion (Figure 4C), suggesting scar formation. An intense glial reaction, with polymorphous nuclear leukocytes, fibroblasts, plasma cells, and edematous cysts, was evident in the areas rostral and caudal to the scar. Although the collagen was rather diffuse and less dense in the MF group, it was negligible in the NP + MF group, indicating absence of scar formation (Figure 4D). However, in the NP + MF group, most of the lesions had epicenters containing cysts, leucocytes, macrophages, and glial cells.

Prussian blue staining identified IONPs in the tissues immediately rostral and caudal to the injury site, which were found to be more concentrated under the influence of an MF in the NP + MF group. The nanoparticles formed clusters and were present on the cell membrane as well as in the cytoplasm of neurons (Figure 6A-C). 

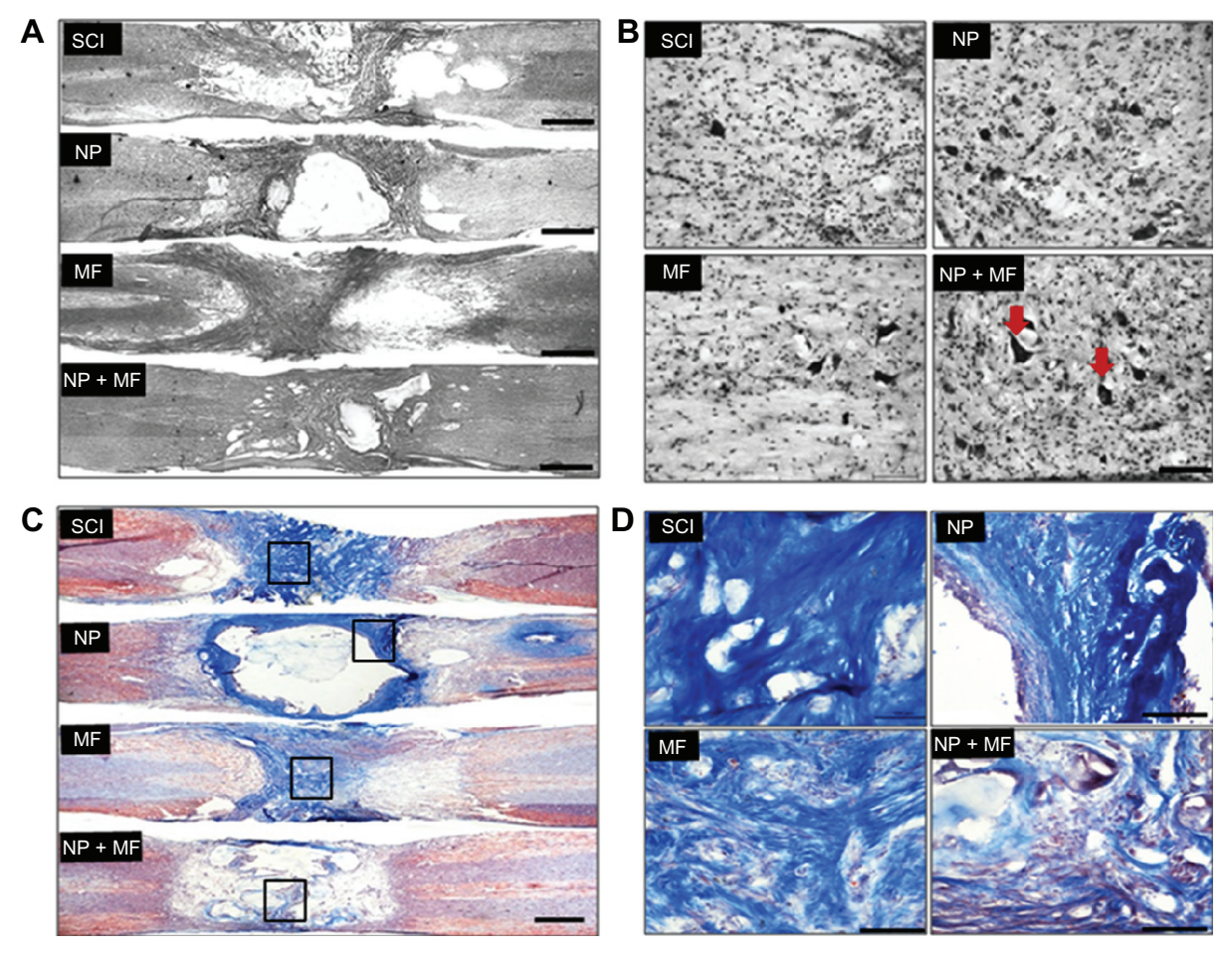

Figure 4 Histological analysis of lesion site. Representative images of stained sections from each group showing extent of the lesion (A) and presence of viable motor neurons (arrowhead) (B) in the NP + MF group. Masson's trichrome staining for collagenous connective tissue (C). Dense collagenous staining was observed in the SCl and NP groups (D), indicating scar formation; this was significantly less in the MF group and was absent in the NP + MF group.

Notes: Scale bar $(\mathbf{A}$ and $\mathbf{C})=1000 \mu \mathrm{m}$ and $(\mathbf{B}$ and $\mathbf{D})=100 \mu \mathrm{m}$.

Abbreviations: IONPs, iron oxide nanoparticles; SCl, spinal cord injury group; $\mathrm{MF}, \mathrm{SCl}+$ magnetic field group; $\mathrm{NP}, \mathrm{SCl}+\mathrm{IONP}$ implantation group; $\mathrm{NP}+\mathrm{MF}, \mathrm{SCl}+\mathrm{IONP}$ implantation + magnetic field group.

\section{Discussion}

This study demonstrates the beneficial effect of IONPs combined with MF exposure in an in vivo rat model of complete SCI. IONP implantation with MF exposure was able to achieve a significant reduction in the functional and morphological deficits observed after SCI in rats. The central nervous system has a limited ability to regenerate and repair after injury, and following complete $\mathrm{SCI}$ in rats, there is complete paralysis of both hind limbs and loss of all motor and sensory function, as observed in the present study. These changes are mainly due

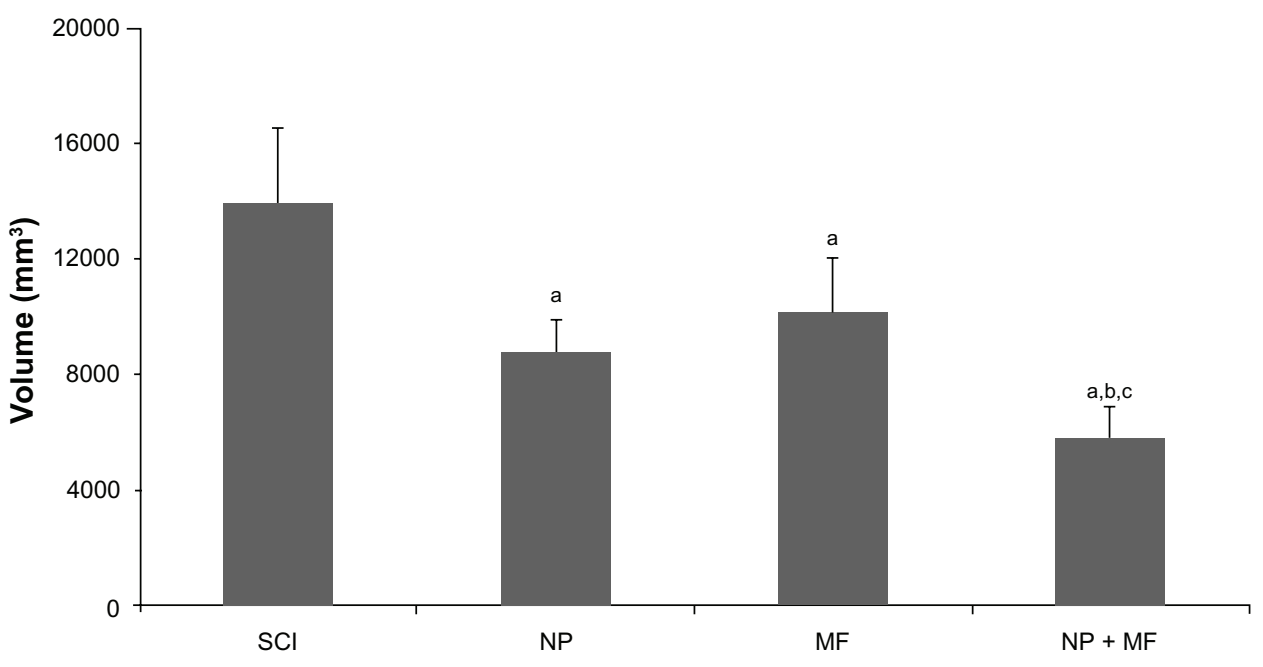

Figure 5 Mean $( \pm S D)$ total tissue damage volume was significantly less in all groups in comparison with the $\mathrm{SCl}$ group, but least in the NP $+\mathrm{MF}$ group.

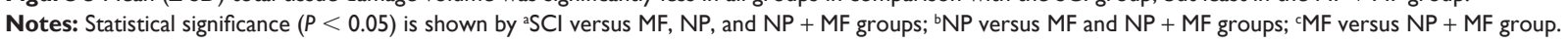
Abbreviations: IONPs, iron oxide nanoparticles; SCl, spinal cord injury group; SD, standard deviation; MF, SCl + magnetic field group; NP, SCl + IONP implantation group; $\mathrm{NP}+\mathrm{MF}, \mathrm{SCl}+\mathrm{IONP}$ implantation + magnetic field group. 


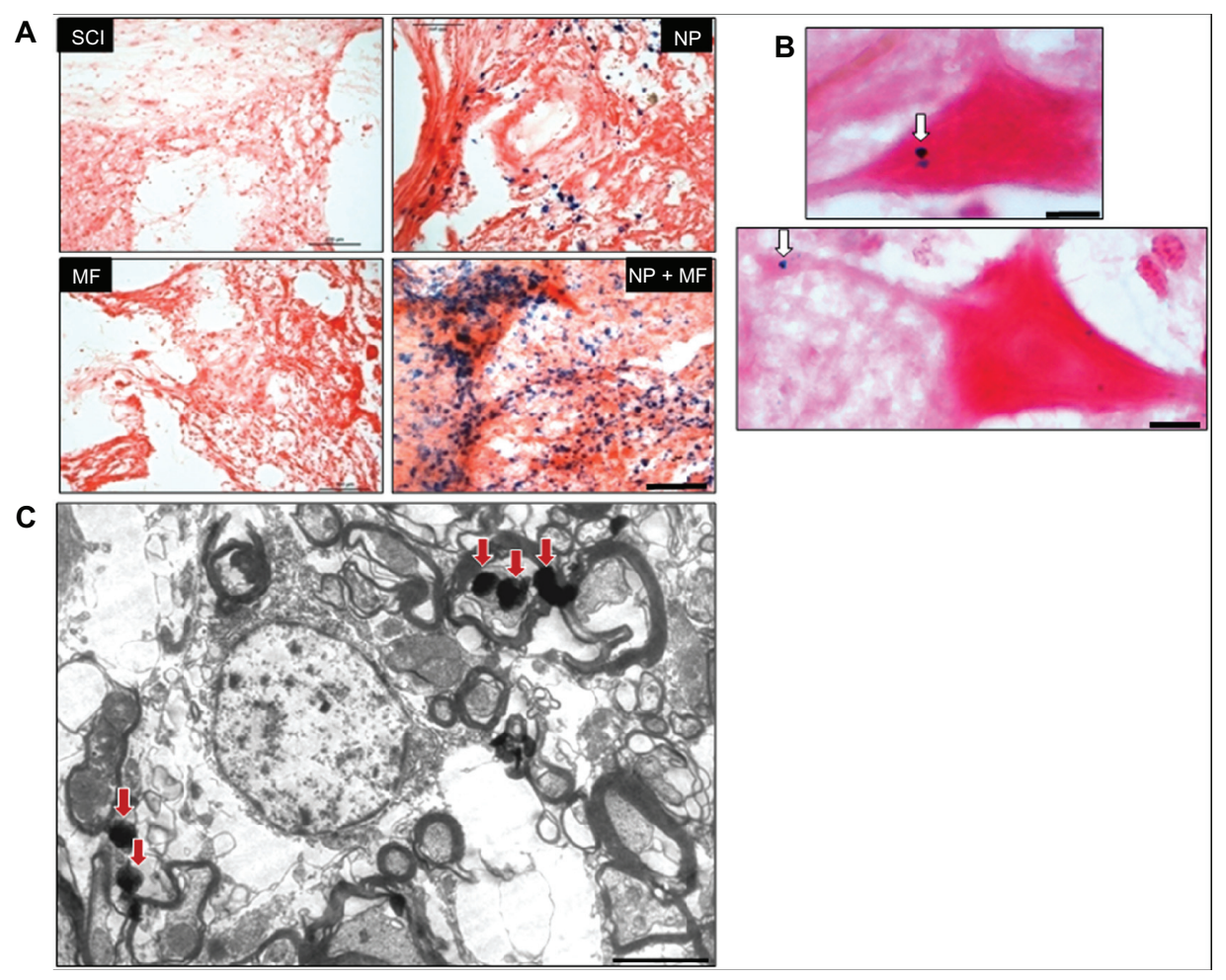

Figure 6 Prussian blue staining for iron (A), showing that IONPs diffused out of the gel and concentrated in tissues near the site of the lesion. This aggregation of IONPs was high in the presence of MF in the NP + MF group. The arrowhead indicates the location of IONPs inside the motor neurons and axons (B). Transmission electron microscope images of tissues showed cytoplasmic localization of IONPs (arrows) (C).

Notes: Scale bar $(\mathbf{A})=100 \mu \mathrm{m},(\mathbf{B})=10 \mu \mathrm{m}$, and $(\mathbf{C})=500 \mathrm{~nm}$.

Abbreviations: IONPs, iron oxide nanoparticles; $\mathrm{SCl}$, spinal cord injury group; $\mathrm{MF}, \mathrm{SCl}+$ magnetic field group; $\mathrm{NP}, \mathrm{SCl}+\mathrm{IONP}$ implantation group; $\mathrm{NP}+\mathrm{MF}, \mathrm{SCl}+\mathrm{IONP}$ implantation + magnetic field group.

to the secondary damage induced by the primary injury that spreads from the epicenter of the injury to the rostral and caudal areas, leading to formation of a scar.-12 In trichrome-stained sections, we also observed thick interconnected bundles of collagenous tissue at the site of the lesion in rats with SCI, suggesting scar formation. A number of edematous cavities and inflammatory cells with no tissue sparing was evident at the site of lesion, extending up to nearly $2 \mathrm{~mm}$ in the rostral and caudal direction, indicating widespread secondary damage. The severity of this damage in the surviving tissue correlates directly with loss of function following SCI. Thus, the complete loss of sensory and motor function associated with deterioration of general condition and bladder dysfunction during the observation period of five weeks is supported by the intensity of the histological changes observed.

MF stimulation creates intense rapid electric fields that can penetrate soft tissue and bone to reach deep nervous structures. If the current created is of sufficient amplitude and duration such that depolarization occurs, neural tissue is stimulated. MF stimulation provides a microenvironment conducive to neural repair by stimulating release of neurotrophic factors that promote migration of glial cells to the site of the lesion and decrease apoptosis after neuronal injury. ${ }^{8} \mathrm{Use}$ of an MF in restoration of locomotion, improving muscle properties, and promoting osteoporosis is extremely beneficial in SCI. ${ }^{31-33,45}$ Bladder control is also restored by functional magnetic stimulation in animal models of SCI and in patients. ${ }^{46-50}$ In the present study, the locomotor behavior, feeding patterns, and body weight of SCI rats exposed to an MF showed significant improvement in comparison with SCI rats not exposed to an MF. Attainment of bladder control also occurred five days earlier in the MF group. These results are comparable with previous reports of repeated low-intensity MF stimulation in SCI rats and may be mediated by the effects of the MF on free radical-induced secondary injury or by activation of the central pattern generator center for locomotion by serotonin pathways. ${ }^{28-36} 5$-Hydroxytryptamine has an important role in modulating the excitability of motor and sensory neurons in the spinal cord, thereby influencing locomotion and sensorimotor behavior. ${ }^{51-55}$ Exposure to an MF has been shown to restore the metabolism, synthesis, and distribution of 5-hydroxytryptamine in the spinal cord and brain. ${ }^{56,57}$ In our study, the lesion volume was significantly reduced by $37 \%$ in the SCI + MF group compared with the SCI group, along with 
minimal collagenous tissue at the site of the lesion, indicating attenuated scar formation and thereby limitation of secondary damage. This may also be responsible for the better functional recovery observed in MF rats. Previous in vitro and in vivo studies demonstrating facilitation of axonal and neuronal regeneration, sparing of white matter, reduction in lesion volume, increased overall cell viability, and a neuroprotective effect against oxidative stressors following MF exposure further support our observations in the MF group. ${ }^{26,29-34}$

IONPs are small-scale structures $(<100 \mathrm{~nm})$ that can be used for biomedical and electronic application and for energy production. Due to their characteristic superparamagnetic and other physical properties, they have attracted much interest for application in vivo. IONPs can be taken up easily by neurons or axons, and along with an MF, provide mechanical tension in the cell membrane, thereby promoting sprout formation and axonal regeneration in vitro. ${ }^{20,21}$ The IONPs used in the present study were localized intracellularly in the neurons lying immediately rostral or caudal to the epicenter. Following implantation of IONPs, the rats were exposed to an MF to promote migration from gel to the tissues and invoke tensile forces to initiate axonal growth. The high density of IONPs found in areas corresponding to the presence of motor neurons and their intracellular localization suggests the possibility of axonal regeneration. Moreover, the implanted IONPs were able to concentrate the MF at the site of lesion, thereby potentiating the effects of exposure to the MF. Therefore, the animals exposed to an MF along with IONPs performed much better than those receiving only MF or IONPs. As shown in the results, there was significantly less loss of body weight, deterioration of feeding, and improvement in locomotor and sensorimotor behavior in the $\mathrm{NP}+\mathrm{MF}$ group even at post-injury week 1 . Spontaneous evacuation of the bladder was achieved around 11 days post-injury, which was much earlier than in any of the other groups. These effects may also be due to a significant reduction in secondary damage in the $\mathrm{NP}+\mathrm{MF}$ group, because there was a decrease in lesion volume by $58 \%$ and trichrome-stained sections showed a complete absence of collagenous tissue scar.

In vitro studies were carried out to accomplish two main objectives: firstly, to observe the cytotoxic effects of
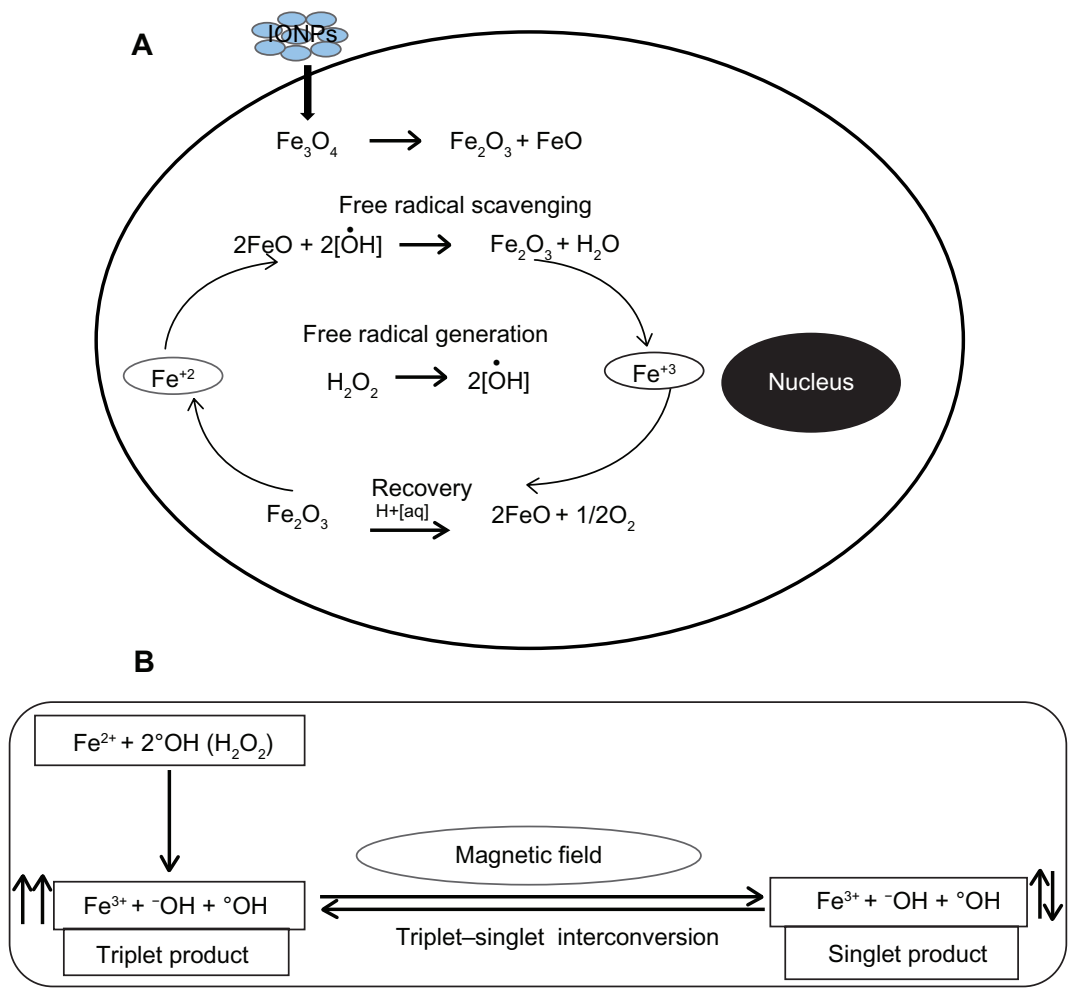

Figure 7 Proposed mechanism for free radical scavenging by IONPs (A) and interaction of radical pairs with MF (B).

Notes: The presence of mixed valence states for $\mathrm{Fe}^{2+}$ and $\mathrm{Fe}^{3+}$ in the $\mathrm{Fe}_{3} \mathrm{O}_{4}$ acts as an antioxidant, enabling the IONPs to scavenge free radicals from the cell. Hydroxyl radical $\left({ }^{\circ} \mathrm{OH}\right)$ produced from $\mathrm{H}_{2} \mathrm{O}_{2}$ reacts with an electron donor $\left(\mathrm{Fe}^{2+}\right)$ and results in generation of a pair of radicals $\left(\mathrm{Fe}^{3+}+{ }^{-} \mathrm{OH}+{ }^{\circ} \mathrm{OH}\right)$ by electron transfer from $\mathrm{Fe}{ }^{2+}$ to ${ }^{\circ} \mathrm{OH}$. An external MF affects interconversion between singlet and triplet states of the radical pair. We believe that low frequency MF leads to spin relaxation and favors generation of a singlet product and prevents generation of oxidative stress by interaction of the triplet product with biomolecules in the cell. Another set of chemical reactions between the ions in the cell and $\mathrm{Fe}_{3} \mathrm{O}_{4}$ then appear to be involved in reversing the oxidation state from $\mathrm{Fe}^{3+}$ to $\mathrm{Fe}^{2+}$. We believe that this is indicative of a cyclical regenerative or autocatalytic reaction on the part of IONPs.

Abbreviations: IONPs, iron oxide nanoparticles; $\mathrm{Fe}^{2+}$, ferrous ion; $\mathrm{Fe}^{3+}$, ferric ion; $\mathrm{MF}$, magnetic field; $\mathrm{H}_{2} \mathrm{O}_{2}$, hydrogen peroxide; ${ }^{-} \mathrm{OH}$, hydroxyl ion; ${ }^{\circ} \mathrm{OH}$, hydroxyl radical; $\mathrm{Fe}_{3} \mathrm{O}_{4}$, iron (II,III) oxide. 
IONPs, and secondly, to clarify the role of IONPs in reducing oxidative stress. We did not observe any cytotoxicity of IONPs at concentrations up to $100 \mu \mathrm{g} / \mathrm{mL}$ with incubation for 72 hours. This is in agreement with the literature, which shows no effect on cell viability at IONP concentrations up to $200 \mu \mathrm{g} / \mathrm{mL}{ }^{22}$ The results of the $\mathrm{H}_{2} \mathrm{O}_{2}$-induced oxidative stress assay in the present study clearly indicate that IONPs have free radical scavenging properties. At 72 hours, only $44 \%$ of cells were found to be viable after incubation with $\mathrm{H}_{2} \mathrm{O}_{2}$ alone, whereas following incubation with $\mathrm{H}_{2} \mathrm{O}_{2}$ and IONPs, viability was increased significantly to $75 \%$. We propose that the presence of the dual valence states of $\mathrm{Fe}^{2+}$ and $\mathrm{Fe}^{3+}$ in the IONPs enables these particles to act as antioxidants, allowing them to absorb free radicals. ${ }^{23}$ IONPs also appear to be involved in reversing the oxidation state from $\mathrm{Fe}^{3+}$ to $\mathrm{Fe}^{2+}$ and vice versa. This suggests that IONPs can participate in cyclical regenerative or autocatalytic reactions (Figure 7A).

Further, the MF also plays an important role in potentiating the antioxidant effect of IONPs. The mechanism proposed for this is as follows: free radicals are very reactive paramagnetic chemical species because they have an odd number of electrons and consequently unpaired electron spins, that may be found in one of two spin states, designated as $\uparrow$ or $\downarrow$. The radical pair is a short-lived reaction intermediate. Two radicals formed in tandem may have their unpaired electron spins either antiparallel $\left(\mathrm{Fe}^{3+}+{ }^{-} \mathrm{OH}+{ }^{\circ} \mathrm{OH}\right.$; $\uparrow \downarrow$, a singlet state with zero total electron spin) or parallel $\left(\mathrm{Fe}^{3+}+{ }^{-} \mathrm{OH}+{ }^{\circ} \mathrm{OH} ; \uparrow \uparrow\right.$, a triplet state with unit spin). Because each electron spin has an associated magnetic moment, the interconversion and chemical fates of the singlet and triplet states can be influenced by the internal (field generated by magnetized IONPs) and external MF. ${ }^{58}$ The interconversion from a triplet to a singlet state by the MF leads to spin relaxation, which is a time-dependent process interfering with the reactive behavior of an excited triplet state (Figure 7B). Thus, interaction between the triplet state and biomolecules in cells may be significantly reduced, leading to decreased generation of free radicals.

\section{Conclusion}

The present study reports significant attenuation of behavioral deficits and secondary damage following implantation of IONPs combined with exposure to an MF in an in vivo rat model of SCI. The antioxidant properties of the IONPs along with spin relaxation by MF appears to be the key to the neuroprotective action of IONPs, that can lead to significant attenuation of the secondary injury cascade following SCI.

\section{Acknowledgments}

We thank Mr Pursottam Samal for histology and Mr Ashish Datt Upadhyay for the statistical analysis. This work was supported by a research grant from the All India Institute of Medical Science Institute. The TEM work was done at the Sophisticated Analytical Instrument Facility, AIIMS, New Delhi.

\section{Disclosure}

The authors report no conflicts of interest in this work.

\section{References}

1. Krassioukov AV, Weaver LC. Morphological changes in sympathetic preganglionic neurons after spinal cord injury in rats. Neuroscience. 1996;70(1):211-225.

2. James ND, Bartus K, Grist J, et al. Conduction failure following spinal cord injury: functional and anatomical changes from acute to chronic stages. J Neurosci. 2011;31(50):18543-18555.

3. Fujieda Y, Ueno S, Ogino R, et al. Metabolite profiles correlate closely with neurobehavioral function in experimental spinal cord injury in rats. PLoS One. 2012;7(8):e43152.

4. Cao T, Thomas TC, Ziebell JM, et al. Morphological and genetic activation of microglia after diffuse traumatic brain injury in the rat. Neuroscience. 2012;225:65-75.

5. Mazzone GL, Nistri A. Electrochemical detection of endogenous glutamate release from rat spinal cord organotypic slices as a real-time method to monitor excitotoxicity. J Neurosci Methods. 2011;197(1): $128-132$.

6. Zhang SX, Huang F, Gates M, et al. Histological repair of damaged spinal cord tissue from chronic contusion injury of rat: a LM observation. Histol Histopathol. 2011;26(1):45-58.

7. Magnuson DS, Trinder TC, Zhang YP, et al. Comparing deficits following excitotoxic and contusion injuries in the thoracic and lumbar spinal cord of the adult rat. Exp Neurol. 1999;156(1):191-204.

8. Wu J, Pajoohesh-Ganji A, Stoica BA, et al. Delayed expression of cell cycle proteins contributes to astroglial scar formation and chronic inflammation after rat spinal cord contusion. $J$ Neuroinflammation. 2012;9:169.

9. Inman DM, Steward O. Physical size does not determine the unique histopathological response seen in the injured mouse spinal cord. J Neurotrauma. 2003;20(1):33-42.

10. Hagg T, Oudega M. Degenerative and spontaneous regenerative processes after spinal cord injury. J Neurotrauma. 2006;23(3-4):264-280.

11. Rooney GE, Endo T, Ameenuddin S, et al. Importance of the vasculature in cyst formation after spinal cord injury. J Neurosurg Spine. 2009; 11(4):432-437.

12. Fitch MT, Doller C, Combs CK, et al. Cellular and molecular mechanisms of glial scarring and progressive cavitation: in vivo and in vitro analysis of inflammation-induced secondary injury after CNS trauma. J Neurosci. 1999;19(9):8182-8198.

13. Klapka N, Muller HW. Collagen matrix in spinal cord injury. J Neurotrauma. 2006;23(3-4):422-435.

14. Hermanns S, Klapka N, Muller HW. The collagenous lesion scar - an obstacle for axonal regeneration in brain and spinal cord injury. Restor Neurol Neurosci. 2001;19(1-2):139-148.

15. Seitz A, Aglow E, Heber-Katz E. Recovery from spinal cord injury: a new transection model in the C57B1/6 mouse. J Neurosci Res. 2002;67(3):337-345.

16. Schiwy N, Brazda N, Muller HW. Enhanced regenerative axon growth of multiple fibre populations in traumatic spinal cord injury following scarsuppressing treatment. Eur J Neurosci. 2009;30(8): $1544-1553$. 
17. Jedlovszky-Hajdu A, Bombelli F, Monopoli MP, et al. Surface coatings shape the protein corona of SPIONs with relevance to their application in vivo. Langmuir. 2012;28(42):14983-14991.

18. El-Dakdouki MH, Zhu DC, El-Boubbou K, et al. Development of multifunctional hyaluronan-coated nanoparticles for imaging and drug delivery to cancer cells. Biomacromolecules. 2012;13(4):1144-1151.

19. Riggio C, Calatayud MP, Hoskins C, et al. Poly-L-lysine-coated magnetic nanoparticles as intracellular actuators for neural guidance. Int J Nanomedicine. 2012;7:3155-3166.

20. De Silva MN, Almeida MV, Goldberg JL. Developing super-paramagnetic nanoparticles for central nervous system axon regeneration. Presented at the 2007 Nano Science and Technology Institute Nanotechnology Conference and Trade Show, Santa Clara, CA, May 7-11, 2007.

21. Halpern AA. Magnetic stretching of magnetized neurons for spinal cord of peripheral nerve repair and regeneration. United State patent US 6132360. October 17, 2000.

22. Naqvi S, Samim M, Abdin MZ, et al. Concentration-dependent toxicity of iron oxide nanoparticles mediated by increased oxidative stress. Int J Nanomedicine. 2010;5:983-989.

23. Chen Z, Yin JJ, Zhou YT, et al. Dual enzyme-like activities of iron oxide nanoparticles and their implication for diminishing cytotoxicity. ACS Nano. 2012;6(5):4001-4012.

24. Fan J, Yin J-J, Ning B, et al. Direct evidence for catalase and peroxidase activities of ferritin-platinum nanoparticles. Biomaterials. 2011;32(6):1611-1618.

25. Prijic S, Scancar J, Romih R, et al. Increased cellular uptake of biocompatible superparamagnetic iron oxide nanoparticles into malignant cells by an external magnetic field. J Membr Biol. 2010;236(1): 167-179.

26. Post A, Muller MB, Engelmann M, et al. Repetitive transcranial magnetic stimulation in rats: evidence for a neuroprotective effect in vitro and in vivo. Eur J Neurosci. 1999;11(9):3247-3254.

27. Fanelli C, Coppola S, Barone R, et al. Magnetic fields increase cell survival by inhibiting apoptosis via modulation of $\mathrm{Ca} 2+$ influx. FASEB J. 1999;13(1):95-102.

28. Poirrier AL, Nyssen Y, Scholtes F, et al. Repetitive transcranial magnetic stimulation improves open field locomotor recovery after low but not high thoracic spinal cord compression-injury in adult rats J Neurosci Res. 2004;75(2):253-261.

29. Lai H, Carino MA, Horita A, et al. Effects of a $60 \mathrm{~Hz}$ magnetic field on central cholinergic system of the rat. Bioelectromagnetics. 1993;14(1): $5-15$.

30. Macias MY, Battocletti JH, Sutton CH, et al. Directed and enhanced neurite growth with pulsed magnetic field stimulation Bioelectromagnetics. 2000;21(4):272-286.

31. Crowe MJ, Sun ZP, Battocletti JH, et al. Exposure to pulsed magnetic fields enhances motor recovery in cats after spinal cord injury. Spine. 2003;28(24):2660-2666

32. Ahmed Z, Wagdy M, Benjamin M, et al. Therapeutic effects of acrobatic exercise and magnetic field exposure on functional recovery after spinal cord injury in mice. Bioelectromagnetics. 2011;329(1):49-57.

33. Ahmed Z, Wieraszko A. Combined effects of acrobatic exercise and magnetic stimulation on the functional recovery after spinal cord lesions. J Neurotrauma. 2008;25(10):1257-1269.

34. Mert T, Gunay I, Gocmen C, et al. Regenerative effects of pulsed magnetic field on injured peripheral nerves. Altern Ther Health Med. 2006;12(5):42-49.

35. Das S, Kumar S, Jain S, et al. Exposure to ELF-magnetic field promotes restoration of sensori-motor functions in adult rats with hemisection of thoracic spinal cord. Electromagn Biol Med. 2012;31(3):180-194.

36. Kumar S, Jain S, Behari J, et al. Effect of magnetic field on food and water intake and body weight of spinal cord injured rats. Indian J Exp Biol. 2010;48(10):982-986.

37. Nishida K, Tanaka N, Nakanishi K, et al. Magnetic targeting of bone marrow stromal cells into spinal cord: through cerebrospinal fluid. Neuroreport. 2006;17(12):1269-1272.
38. Shula S, Jeff S, Chris B, et al. Templated agarose scaffolds support linear axonal regeneration. Tissue Eng. 2004;12(10):2777-2787.

39. Basso DM, Beattie MS, Bresnahan JC. Graded histological and locomotor outcomes after spinal cord contusion using the NYU weight drop device versus transection. Exp Neurol. 1996;139(2):244-256.

40. Kirschvink JL. Uniform magnetic fields and double-wrapped coil systems: improved techniques for the design of bioelectromagnetic experiments. Bioelectromagnetics. 1992;13(5):401-411.

41. Basso DM, Beattie MS, Bresnahan JC. A sensitive and reliable locomotor rating scale for open field testing in rats. $J$ Neurotrauma. 1995;12(1):1-21.

42. Faulkner JR, Herrmann JE, Woo MJ, et al. Reactive astrocytes protect tissue and preserve function after spinal cord injury. J Neurosci. 2004; 24(9):2143-2155.

43. Nera T, Sato S, Obato H, et al. A rat model of post-thoracotomy pain: behavioral and spinal cord NK-1 receptor assessment. Can J Anesth. 2001;48(7):665-676.

44. Liebscher T, Schell L, Schnell D, et al. Noga-A antibody improves regeneration and locomotion of spinal cord injured rats. Ann Neurol. 2005;58(5):706-719.

45. Shen WW, Zhao JH. Pulse electromagnetic field stimulation affects BMD and local factor production of rats with disuse osteoporosis. Bioelectromagnetics. 2010;31(2):113-119.

46. Abdel-Gawad M, Boyer S, Sawan M, et al. Reduction of bladder outlet resistance by selective stimulation of the ventral sacral root using high frequency blockade: a chronic study in spinal cord transected dogs. J Urol. 2001;166(2):728-733.

47. Lin VW, Wolfe V, Perkash I. Micturition by functional magnetic stimulation. J Spinal Cord Med. 1997;20(2):218-226.

48. Lin VW, Hsiao I, Xu H, Bushnik T, Perkash I. Functional magnetic stimulation facilitates gastrointestinal transit of liquids in rats. Muscle Nerve. 2000;23(6):919-924.

49. Lin VW, Nino-Murcia M, Frost F, et al. Functional magnetic stimulation of the colon in persons with spinal cord injury. Arch Phys Med Rehabil. 2001;82(2):167-173.

50. Lin VW, Kim KH, Hsiao I, et al. Functional magnetic stimulation facilitates gastric emptying. Arch Phys Med Rehabil. 2002;83(6): 806-810.

51. Antri M, Orsal D, Barthe JY. Locomotor recovery in the chronic spinal rat: effects of long-term treatment with a 5-HT2 agonist. Eur J Neurosci. $2002 ; 16(3): 467-476$.

52. Hulsebosch CE, Hain BC, Crown ED, et al. Mechanisms of chronic central neuropathic pain after spinal cord injury. Brain Res Rev. 2009;60(1):202-213.

53. Sharma HS, Olsson Y, Dey PK. Early accumulation of serotonin in rat spinal cord subjected to traumatic injury, relation to edema and blood flow changes. Neuroscience. 1990;36(3):725-730.

54. Costa JL, Ito U, Spatz M, et al. 5-hydroxytryptamine accumulation in cerebrovascular injury. Nature. 1974;248(444):135-136.

55. Nemecek S, Suba P, Cerman J. Serotonin in contused spinal cord. Acta Neurochir (Wien). 1977;39(1-2):53-58

56. Magnusson T. Effect of chronic transection on dopamine, nor-adrenaline, 5-hydroxytryptamine in the rat spinal cord. Naunyn Schmiedebergs Arch Pharmacol. 1973;278(1):13-22.

57. Schubert J. Effect of spinal transection on the metabolism of 5-hydroxyindoles formed in vivo from $3 \mathrm{H}$-tryptophan in the rat spinal cord. Acta Physiol Scand. 1973;87(4):557-566.

58. Zaporozhan V, Ponomarenko A. Mechanisms of geomagnetic field influence on gene expression using influenza as a model system: basics of physical epidemiology. Int J Environ Res Public Health. 2010;7(3): 938-965. 


\section{Publish your work in this journal}

The International Journal of Nanomedicine is an international, peerreviewed journal focusing on the application of nanotechnology in diagnostics, therapeutics, and drug delivery systems throughout the biomedical field. This journal is indexed on PubMed Central, MedLine, CAS, SciSearch ${ }^{\circledR}$, Current Contents ${ }^{\circledR} /$ Clinical Medicine,

Journal Citation Reports/Science Edition, EMBase, Scopus and the Elsevier Bibliographic databases. The manuscript management system is completely online and includes a very quick and fair peer-review system, which is all easy to use. Visit http://www.dovepress.com/ testimonials.php to read real quotes from published authors.

Submit your manuscript here: http://www.dovepress.com/international-journal-of-nanomedicine-journal 